\title{
SUBSIDENCE HAZARDS AS A CONSEQUENCE OF DAM, RESERVOIR AND TUNNEL CONSTRUCTION
}

\author{
Petar MILANOVIC
}

\begin{abstract}
Considering all man-made structures in karst areas, dams, reservoirs and tunnels are the most vulnerable in relation to induced subsidence and caverns. Reservoirs that are located entirely or partially on karstified rocks covered with unconsolidated sediments are especially subsidence-prone. As a consequence of induced subsidence a number of reservoirs in karst areas failed and were never fully filled. Such subsidence formation is very damaging because the development is unpredictable and practically instantaneous. Reservoirs in karst areas may fail to fill despite an extensive site investigation programs and sealing treatment. Every problem is unique and past experiences are never repeated.

This review focuses on the meaning and consequences of selected prominent examples, but the conclusions reached are valid for subsidence problems related to man-made structures in general.
\end{abstract}

KEY WORDS: karst, karst subsidence hazard

\section{Introduction}

The centuries-old problem of dewatering karst poljes and other depressions has forced the inhabitants of karst regions to maintain constant swallowing conditions in subsidence ponors. At numerous sites in the Dinaride, Helenide and Tauride regions, remains of constructions intended to prevent material being washed into and filling the entrance sections of ponors are visible. To prevent erosion of agricultural soils, great attempts have been made to plug subsidence ponors and estavelles, using natural materials such as stone, wood and clay (Fig. 1).

Overburden thickness in subsidence-prone areas varies from a few meters to more than $70 \mathrm{~m}$. Subsidence in reservoir floors and banks occurs under the influence of water (groundwater, flood water and pore water), as erosion and piping action break down the support of poorly consolidated sediments. In some cases, water under pressure (water hammer) or water pressurizing air in the aeration zone (air hammer), has triggered blow-outs through overlaying sediments.

In some cases subsidences that originated within the alluvial floors of reservoirs are connected with long, wide and very deep cracks.

During dam construction the presence of caverns poses unique problems. In 


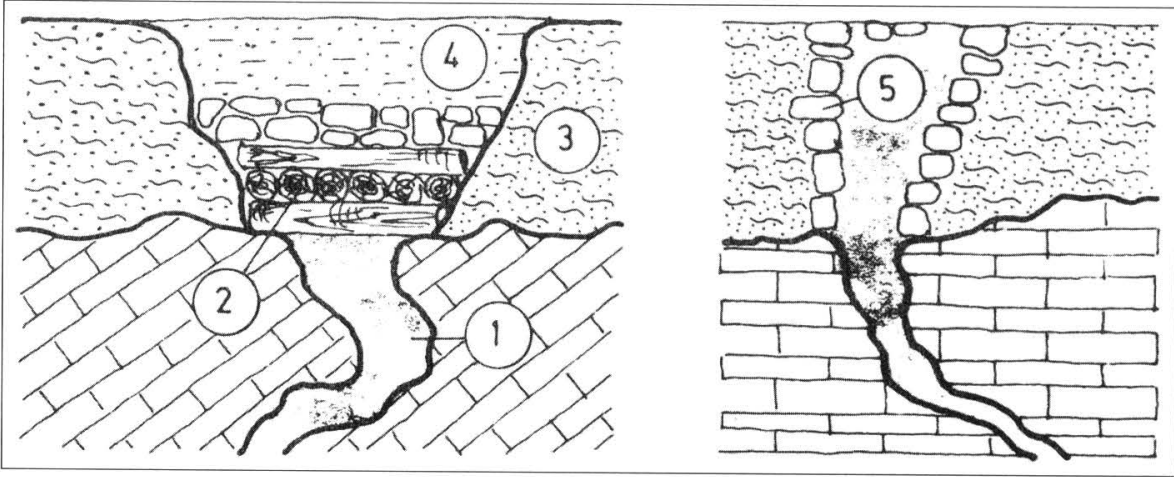

Fig. 1 - Ancient subsidence protection solutions. $1=$ Karst channel; $2=$ Wooden structure with stone loading; $3=$ Alluvial deposits; $4=$ Soil cover and $5=$ Walled-in subsidence .

extreme cases, caverns may be large and extensive enough to defy geotechnical solution. The most common technical difficulties are water leakage at dam sites and from reservoirs, and as a consequence, subsidence development (origin) within the reservoir.

Defects that propagate during underground excavation, especially tunneling, in karst can cause undesirable effects at the surface, especially in situations with thin overburden. Defects that develop during tunnel operation are also very common in karst environments.

Subsidence along river beds and beneath dikes and embankments can give rise to considerable damage during hydrotechnical construction operations.

\section{Subsidences in reservoirs}

Subsidence development is a very common process, which endangers the safety and integrity of reservoirs. Subsidence induced by filling or due to extensive water level fluctuation in man-made situations has resulted in significant leakage from certain reservoirs (Hutovo Reservoir - Popovo Polje, Herzegovina, $3 \mathrm{~m}^{3} / \mathrm{s}$; Vrtac Niksicko Polje, Yugoslavia, 25 m³/s; Keban - Turkey, $26 \mathrm{~m}^{3} / \mathrm{s}$; Mavrovo Reservoir Macedonia, 7 m³/s; Perdika Reservoir - Greece; and many others).

The paleorelief beneath unconsolidated sediments deposited in karst depressions and river valleys has typical karst morphology, including sinkhole and swallowhole (ponor) features. During sedimentation these features were covered with deposits of clay, terra-rossa, gravel, cobbles and boulders. All karst features, including the openings of swallowholes (ponors), were partly or completely plugged. In this way connection with the underlying karst aquifer is partially or totally prevented.

Man-made reservoirs change the regime of underground and surface water, provoking many different destructive processes, including suffosion, erosion, air hammer and water hammer effects.

Suffosion (mechanical suffosion) may be activated from the surface by flood water or from below by underground water. After an initial channel has formed as a consequence of flood water, suffosion and erosion processes occur. Large volumes of 
eroded material are transported through the karst channels. Subsidences in the form of funnel-like shafts, originating at the surface (reservoir floor or banks), are the locations of concentrated water leakage.

In places where the karst channel is covered with unconsolidated sediments, strong upward flow can provoke fluidization and the piping process. The final result is the same as in the previous case, ie the collapse of the overlying alluvial layers is of subsidence origin.

Karst poljes are very sensitive from the subsidence point of view, and the subsidence prone zones can occur anywhere. During the dry period of the year the water table is deep below the polje bottom, but during the wet seasons the water table rises abruptly and a considerable part of the reservoir floor is under the influence of strong uplift. Subsidences and huge open cracks in the reservoir bottom appear as a result. Good examples are provided by reservoirs in karst poljes in the Dinaric karst.

The Hutovo reservoir, located at the lowest part of the large Popovo Polje karst depression (Herzegovina), is a good example of induced subsidence occurrence. The reservoir floor is covered with alluvial deposits, which increase in thickness from the flanks, reaching about $30 \mathrm{~m}$ towards the middle part of the polje. The Cretaceous limestone bedrock topography is typical for karst.

The reservoir area was losing water under natural conditions through 75 recorded ponors, represented by different sized subsidences. The largest was formed above the fossilized ponor of the river Trebisnjica (Fig. 2).

By applying different investigation methods (geological mapping, geophysical investigations and close spacing drilling) the fossilized opening of a ponor was detected at depth of $50 \mathrm{~m}$ beneath the floor level. Fig. 3 shows contour lines of paleo karst relief (a) and a cross-section (b) through the infilled karstic sinkhole with fossilized ponor at the very bottom. Presently, the swallowing capacity of the ponor is drastically limited.

Before the reservoir was filled the ponor was only active from time to time. During the reservoirs operation, despite surface treatment, a number of large subsidences occurred. 38 new subsidences developed after the first impounding, followed by 44 in the next year and 36 during the third year of operation.

The subsidence zone was rendered impermeable by grouting the karstified paleorelief. Pressure grouting with a cement mixture was introduced from the surface. After grouting of the bedrock, the channels in the alluvial parts of the ponors were filled in with grout mix. A grouting mix with the approximate characteristics of the surrounding material (the proportion of clay was increased with respect to cement) was used.

In this area pressurized air plays an important role in subsidence formation. During dry periods the water table is very deep (100 or more meters below the surface). Short periods of heavy precipitation lead to flash flooding of the reservoir floor and an extremely rapid rise of the water table (50 - $80 \mathrm{~m}$ within 24 hours).

As a consequence, large volumes of air become trapped in some caverns, as shown in Fig. 4a. This air does not have time to escape, because the surface layer of soil is rapidly saturated with water. Therefore, air becomes entrapped and pressurized (Fig.4b). When the pressure exceeds the strength of the overlying alluvial layers, air 


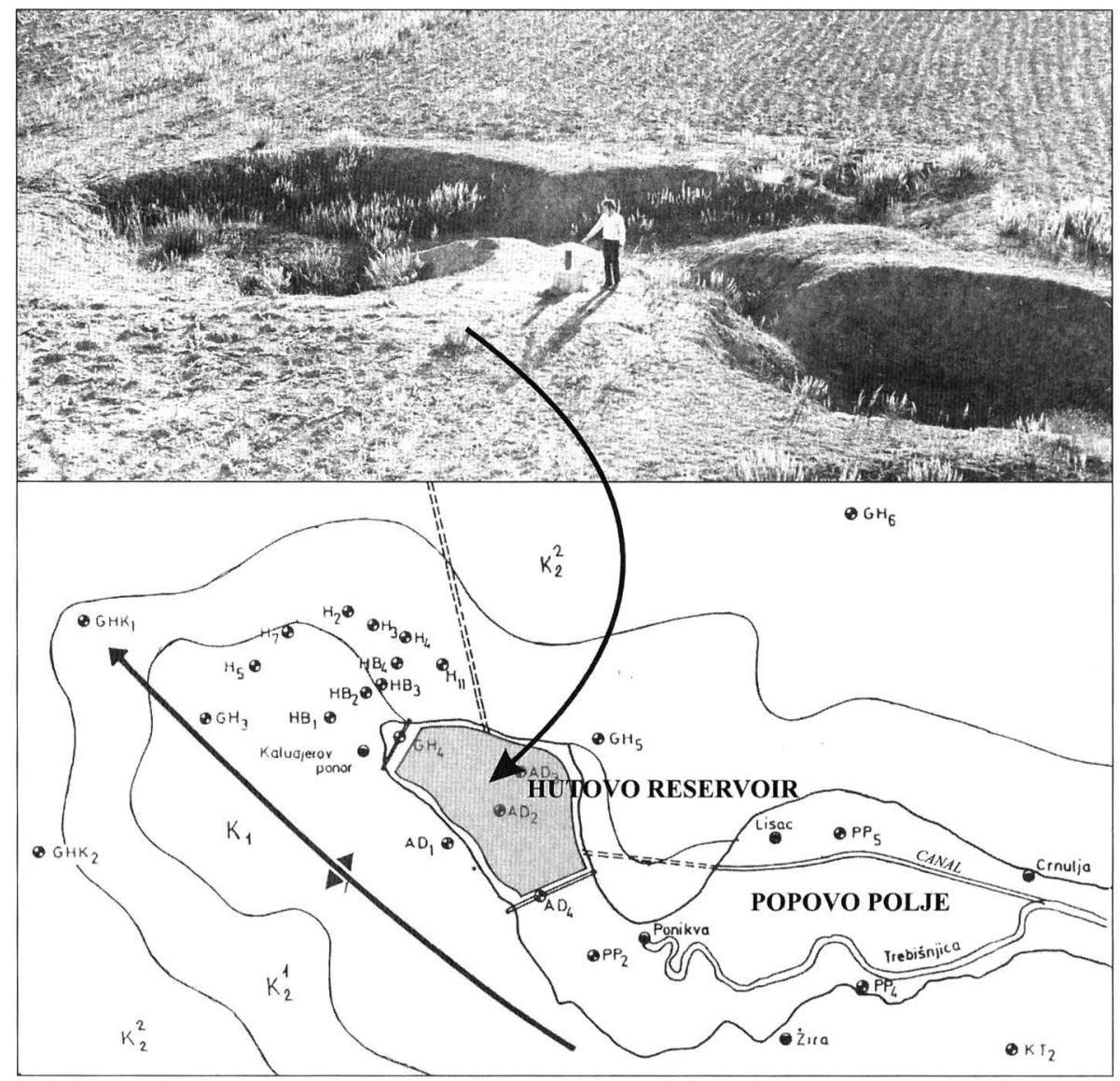

Fig. 2 - The main subsidence area in the Popovo Polje - Hutovo Reservoir.

eruption destroys this zone. At the surface this has been observed as fountain-like eruptions. After water table depression beneath the area of destroyed sediments, water sinks through newly created ponors (c).

In some cases reinforced shotcrete is not sufficiently resistant against strong uplift pressures (Fig. 5).

A need was foreseen to introduce aeration pipes through the alluvial cover and down to the karst channel in the bedrock, to allow timely evacuation of confined air. The tops of these pipes were set above the maximum expected levels of water in the reservoir (Fig. 6).

After rendering the reservoir floor impermeable by compaction, two-dimensional defects developed, in the f $^{\circ}$ orm of wide and long fissures in alluvium. Fissure widths ranged between 1 and $30 \mathrm{~cm}$, and lengths from a few meters to a hundred meters. Such features were found even under the protective plastic membrane. New subsidences also originated along some of the fissures, especially at points of fissure inter- 


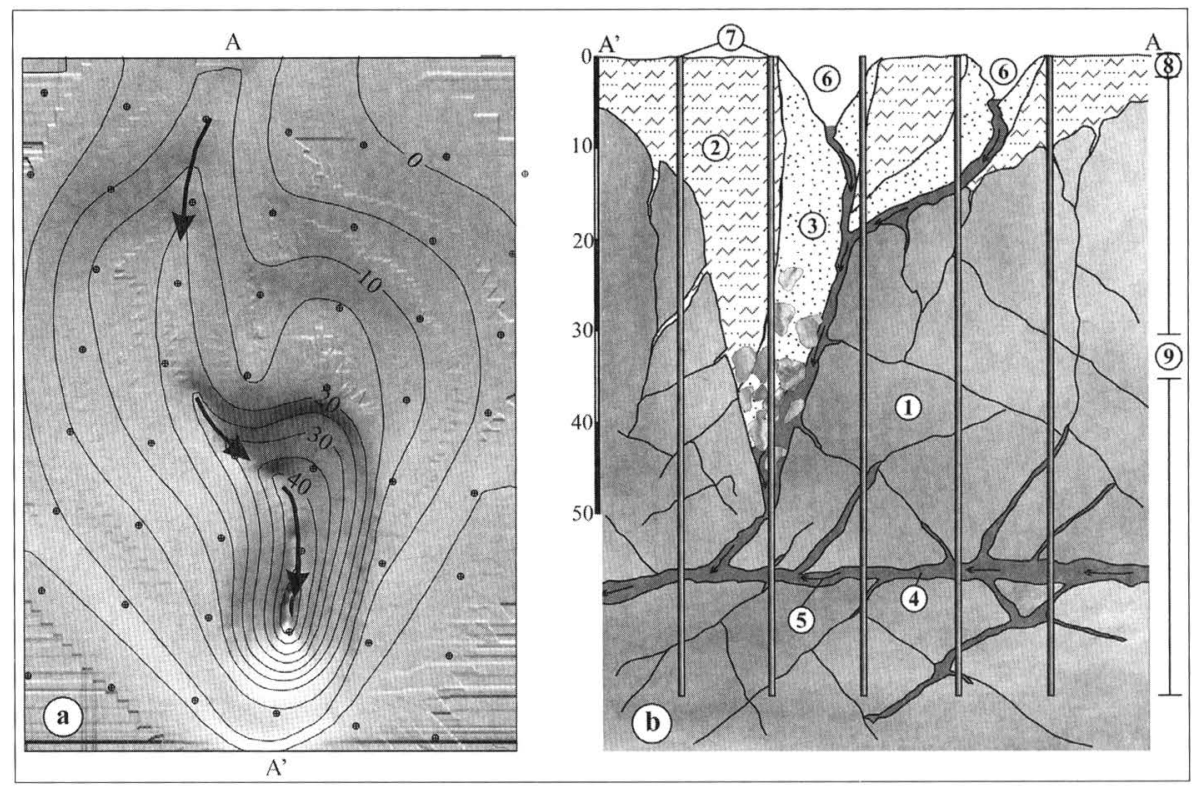

Fig. 3 - Main subsidence - temporarily active ponor (Hutovo Reservoir): $(a)=$ Contour lines of paleorelief and locations of investigation boreholes. Arrows indicate trace of fossil river bed toward the main ponor; $(b)=$ Cross-section: $1=$ Karstified limestone, $2=$ Alluvial deposits; $3=$ Degraded zone in alluvial deposits; $4=$ Karst channel; $5=$ Direction of underground flow; $6=$ Subsidence; $7=$ Investigation boreholes; $8=$ Zone treated by compaction, and $9=$ Zone treated by grouting.

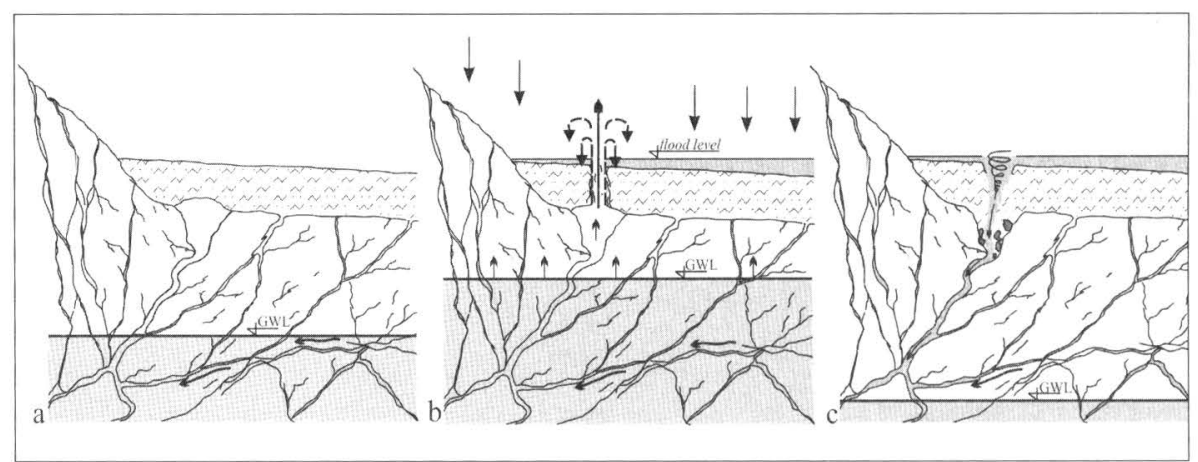

Fig. 4 - Subsidence created by air-hammer effects

section. In some cases subsidences developed between two parallel cracks (Fig. 7).

Both features appeared after reservoir filling and a short time in operation. The fissures were already visible when the reservoir floor was covered with water.

After a sudden rise of water table in the karst aquifer beneath the polje, it was found that air circulated even through piezometers installed in the reservoir area. Due to the abrupt water level rise the air current from the piezometric pipes and aeration 


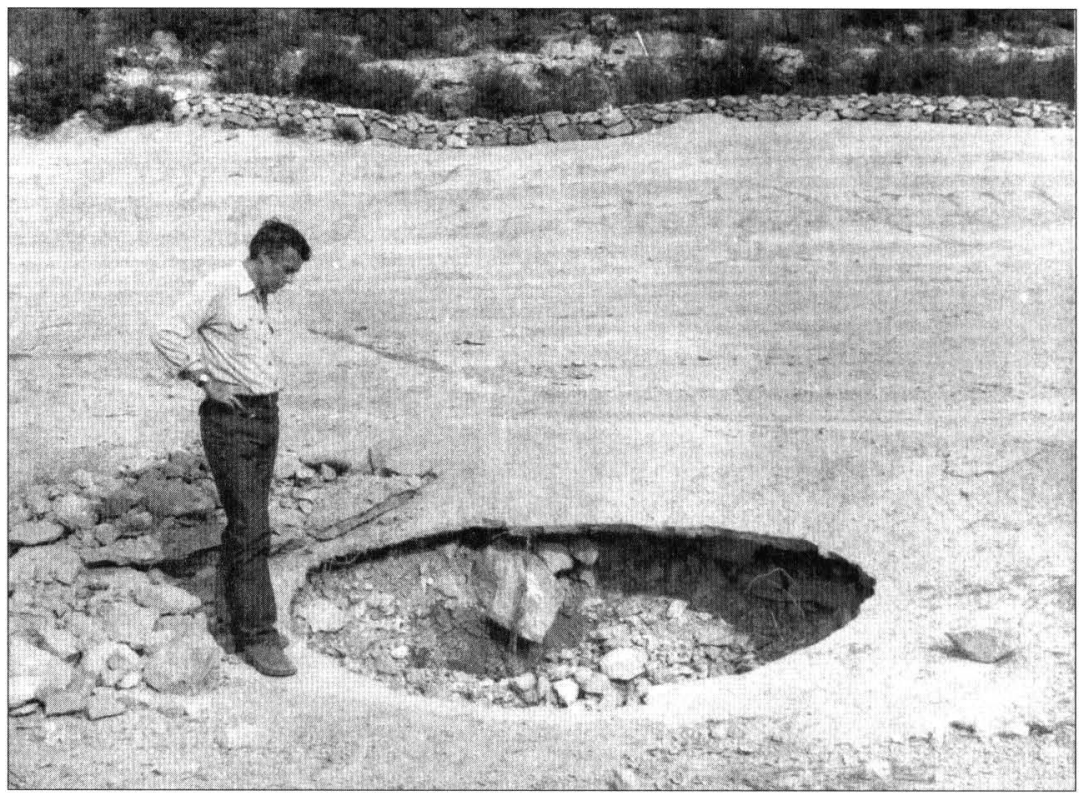

Fig. 5 -Subsidence created in a shotcrete protective layer by strong groundwater uplift.

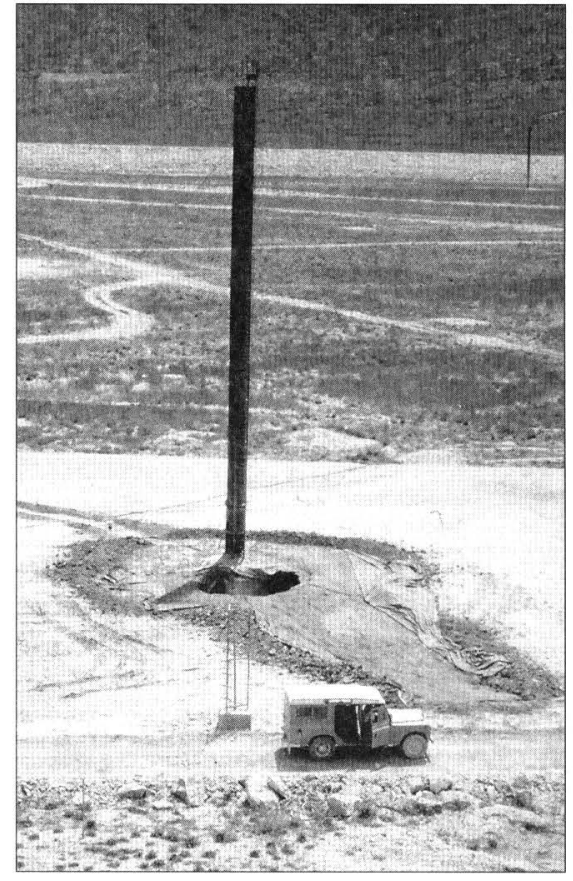

Fig. 6 - Aeration pipe.

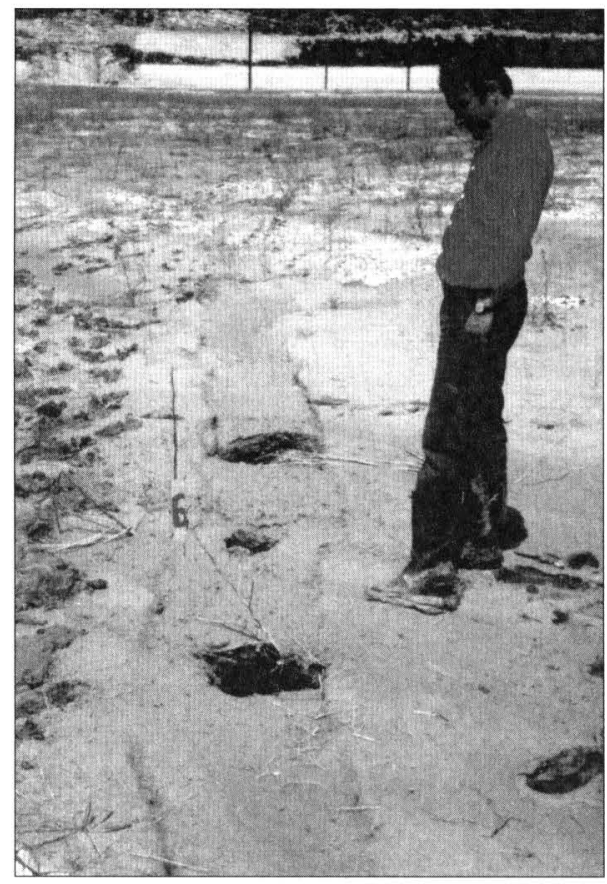

Fig. 7 - Subsidence developed between two parallel cracks. 
pipes reached a velocity of $15 \mathrm{~m} / \mathrm{s}$. It was also found that this circulation was pulsatory, expelling and sucking in air with a periodicity of 17 to 35 minutes. This pulsation was recorded only when the water table was rising, never when it was falling.

A particular problem is presented in the case of estavelles in the storage reservoirs. Because of its double hydrogeological function every estavelle is a potential subsidence site. In order to improve the water-tightness of Vrtac reservoir in Niksic Polje, Yugoslavia, several sealing methods were applied (cylindrical dams, plugging of ponors, non-return valves and concrete blankets). Unfortunately, all these measures were unsuccessful. After the first reservoir filling and a strong water table rise during the wet season, the groundwater could not discharge through the natural estavelle openings. As a consequence more than 100 new subsidences were formed in the reservoir floor (Fig. 8).

Successfully rendering reservoir floor subsidences impermeable does not ensure that the process of new subsidence development will definitely came to an end. The case of Mavrovo Reservoir, Macedonia, is a good example. At the time of first filling (1960) two large and several small subsidence ponors developed in the alluvial cover overlying the karstified marble limestone, and about $9-12 \mathrm{~m}^{3 /} / \mathrm{s}$ of water escaped from the reservoir. The subsidence ponors were filled with crushed stone and covered with a protective impervious blanket, $70 \mathrm{~m}$ wide and $430 \mathrm{~m}$ long. During its next 25 years of operation (until 1986) the reservoir was never filled to the designed operational level. Permanent reservoir fluctuation led to the washing out of the cave

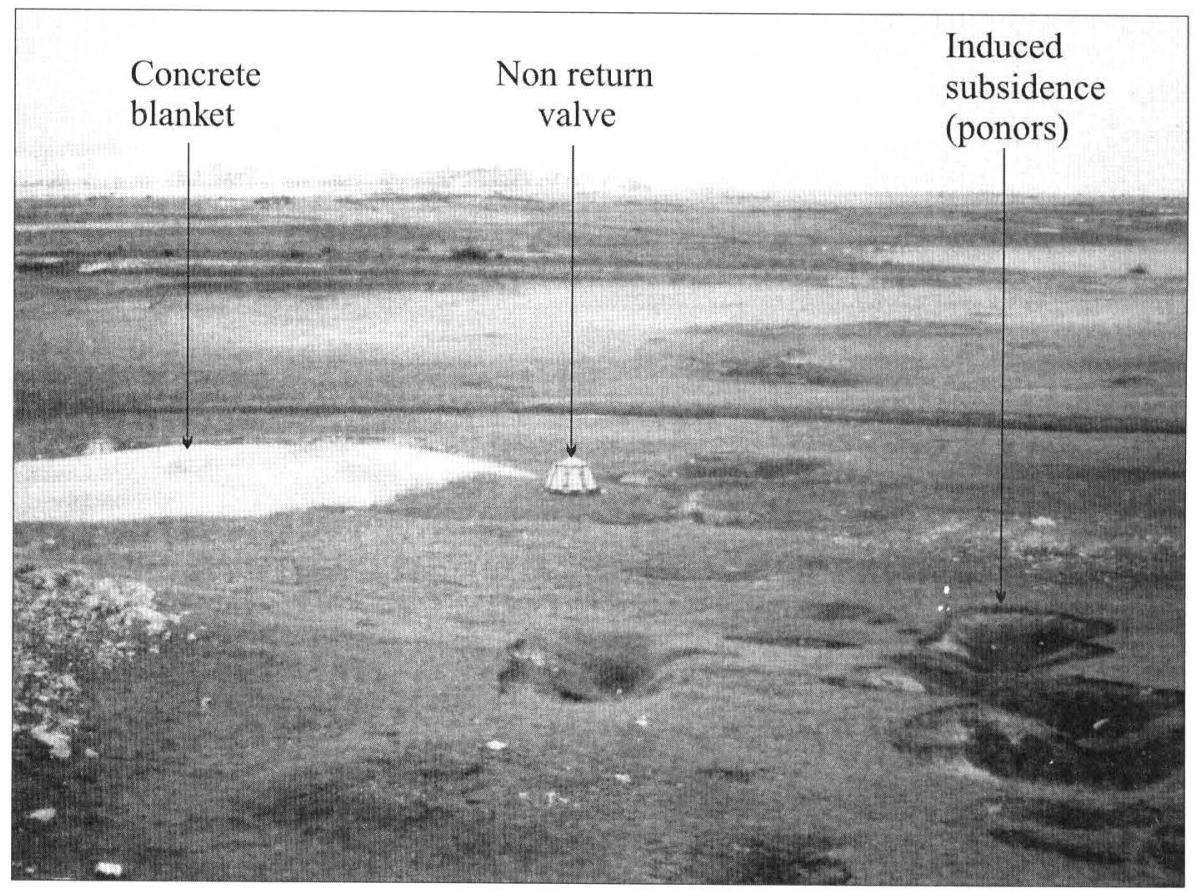

Fig. 8 - Niksic Polje. Subsidence induced by reservoir operation. 
fill sediments, finally creating erosion channels in the alluvial cover. During the very rainy year of 1986, abrupt water level increase served as a trigger to development of subsidences (Fig. 9).

Some of the subsidences were formed within the blanket zone, but more of them developed in the natural deluvial cover overlying the marbleized limestone. These subsidences provoked considerable environmental impact in the form of heavy damage to local roads and surrounding houses. A wide range of geological and geophysical investigations have been carried out to determine the actual conditions, to ensure selection of an appropriate impermeability treatment. Finally, the subsidence (ponor) zone was isolated from the reservoir by construction of an earth filled dyke.

The floor of the May Reservoir in Turkey comprises a $15-20 \mathrm{~m}$-thick alluvial layer, overlying karstified limestone, conglomerate and marl. During the first filling of the reservoir many subsidence ponors opened in the floor of the downstream part of the reservoir, as well as along the right bank close to the rock fill dam. The reservoir leakage led to a severe reduction in the usage of the stored water.

The Keban Dam, in Turkey, is situated in a deeply karstified ridge of metamorphic marble and limestone, including beds of dolomite and calcareous schist of Paleozoic age. During the first filling of the reservoir a large vortex was observed on the left abutment, $150 \mathrm{~m}$ upstream of the dam crest. A large subsidence, connected with a huge cav-

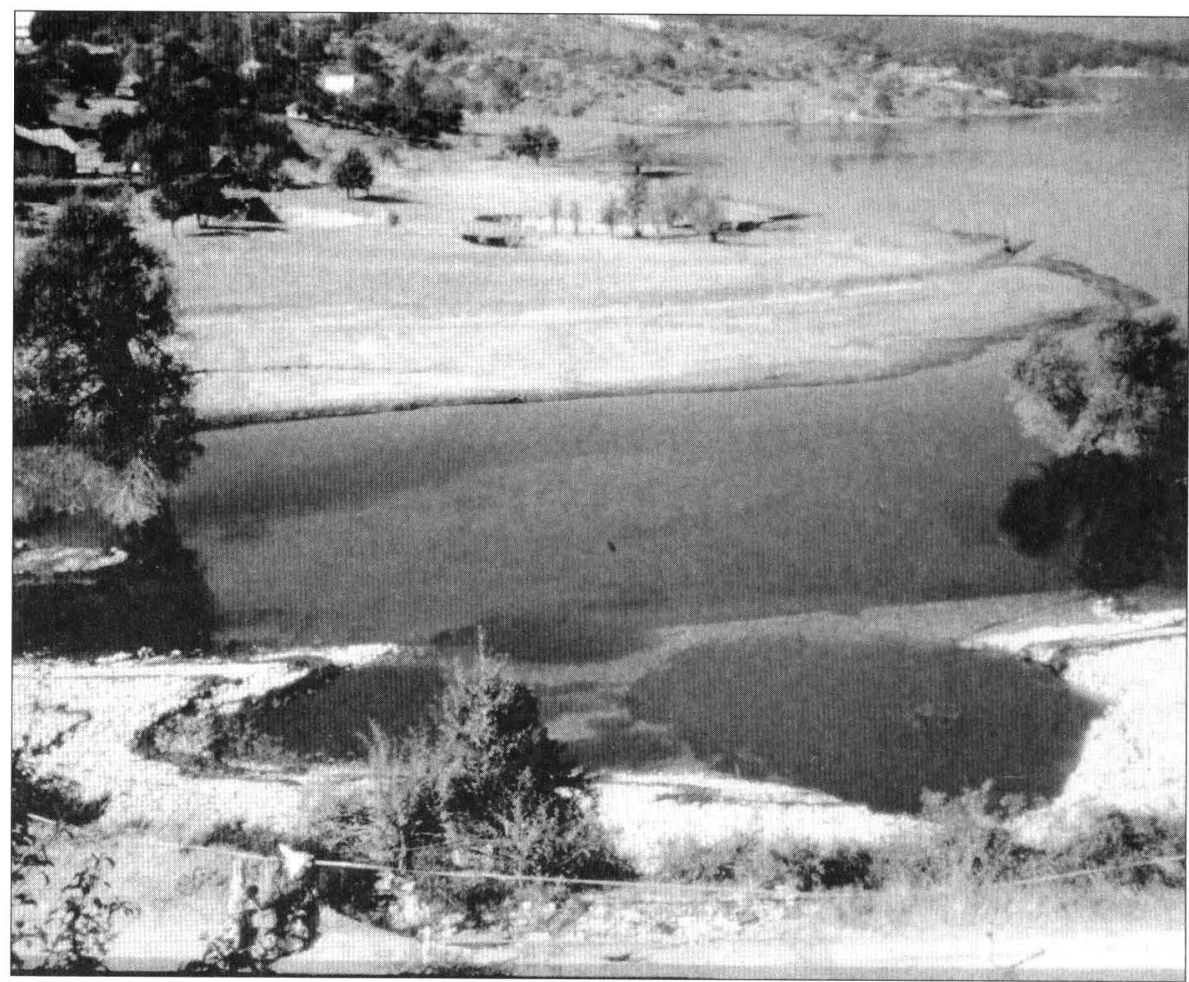

Fig. 9 - Mavrovo Reservoir. Subsidence induced by reservoir operation. 
ern, was created in the thin alluvial cover. Water losses from the reservoir increased to $26 \mathrm{~m}^{3} / \mathrm{s}$. In an attempt to minimize water losses, about $600,000 \mathrm{~m}^{3} / \mathrm{s}$ of limestone blocks, gravel, sand and clay were dumped into the cave through an excavated shaft 2.5 $\mathrm{m}$ in diameter, and through 13 boreholes of 14 to 17 inches in diameter.

The Perdika Reservoir, in Greece, is situated in karstified Upper Cretaceous limestone. Plio-Pleistocene sediments (clayey silts, silty sand, coarse sand and gravel) on the reservoir floor vary in thickness from zero to more than $90 \mathrm{~m}$ (Pantzartzis et al, 1993).

During its first filling, numerous ponors, cracks and subsidences occurred inside the reservoir. There was no relation between the development of subsidences and the thickness of the overburden. Groundwater level was about $70 \mathrm{~m}$ below the reservoir floor. Rehabilitation measures were not successful.

In some cases subsidence development is not a consequence of groundwater filtration out of a reservoir. It occurs as a consequence of frequent and high amplitude fluctuation in deep reservoirs, particularly if the amplitudes are more than $50 \mathrm{~m}$. Intensive, but local, suffosion processes between the upper and lower parts of the same bank of the Bileca reservoir (Herzegovina) provoked a few subsidences in the upper section (Fig. 10).

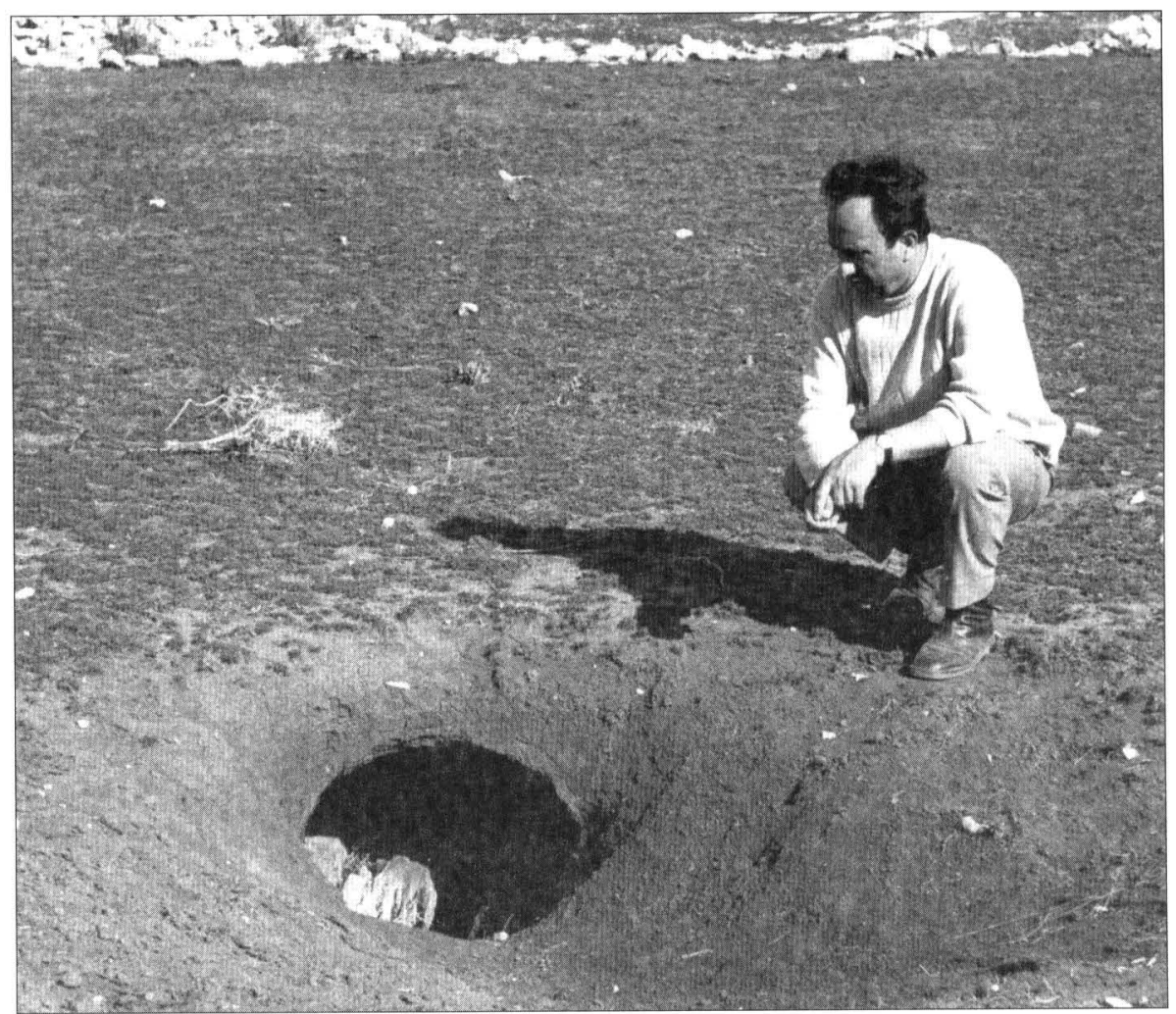

Fig. 10 - Bileca Reservoir. Subsidence created by local water filtration. 


\section{Problems with caverns and subsidences in underground excavation}

Defects encountered during underground excavations and tunnelling operation in karst can provoke undesirable effects at the surface. Any fault or cavernous zone that connects a tunnel section with the surface holds potential for subsidence, especially in the case of thin overburden (Fig. 11). The collapse prone areas are particularly susceptible in the case of hydrotechnical tunnels, especially derivation high-pressure tunnels.

Subsidences created during tunnelling operations are illustrated by the following example. Water leakage from a headrace tunnel tube eroded and washed away unconsolidated cave deposits in the section where the tunnel intersected a large filled cavern (Fig. 12).

Percolation through the tunnel lining caused intensive erosion and transport of great volumes of sandy-clay cave deposits toward deeper channel sections over time. This resulted in the development of an empty space around the tunnel tube, and formation of subsidence at the surface. Particularly dangerous was the washed-out part of the cavern situated below the lining, with a length of $16 \mathrm{~m}$, a width of about $7 \mathrm{~m}$ and a depth of 8 to $15 \mathrm{~m}$. The loss of support seriously endangered the stability of the tunnel tube.

Complex investigation work has been carried out, including drilling, water level monitoring, measurements of leakage, geological analysis, speleological investigations, TV logging and tracing tests by dye and smoke tracers (Fig. 13). Speleological investigations, including detailed mapping of surface subsidence and underground collapse, were very successful.

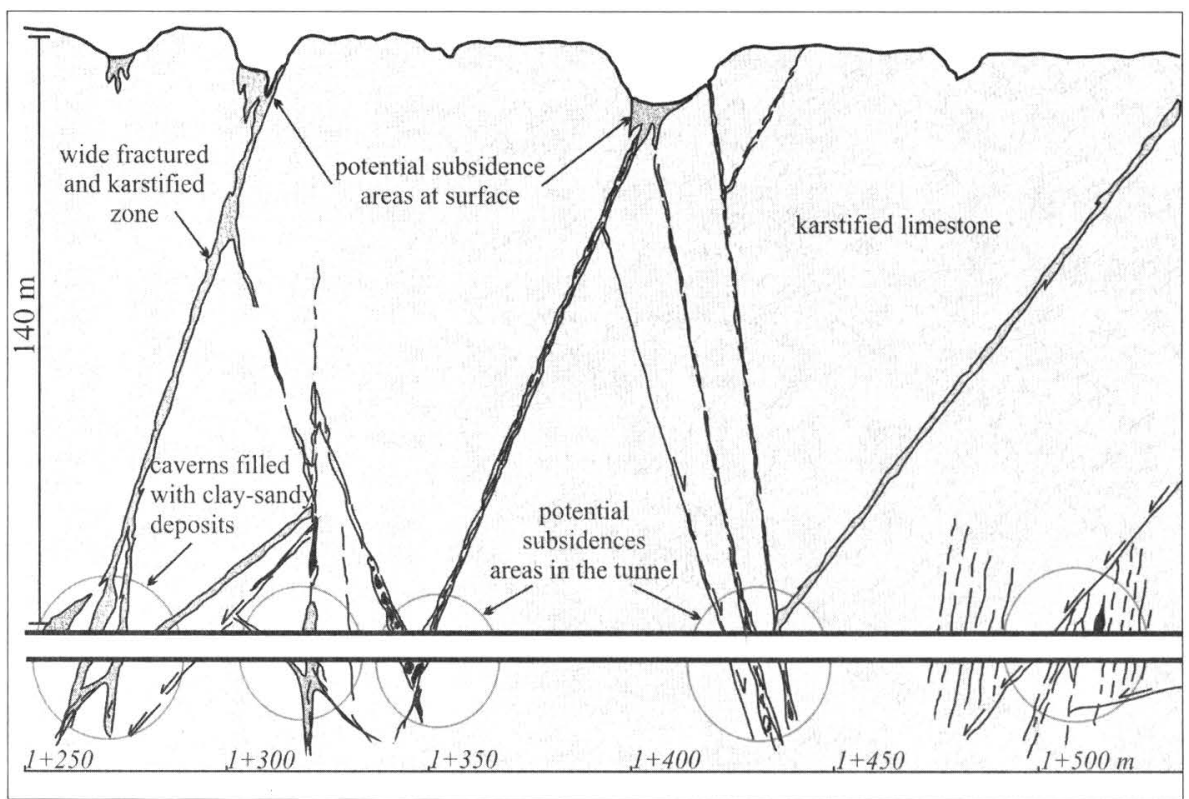

Fig. 11 - The Dabar - Fatnica Tunnel. Potential subsidence zones. 


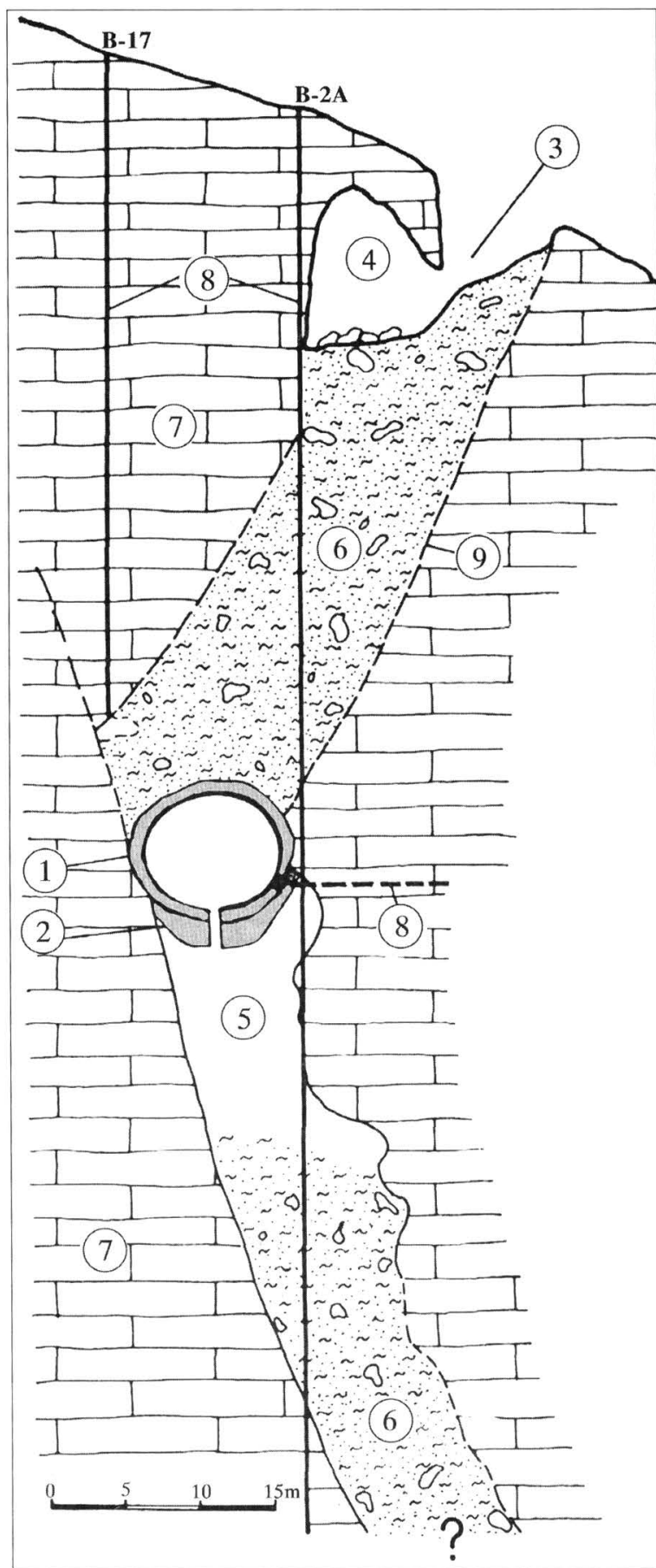

Fig. 12 - Headrace tunnel for HPP Capljina. Subsidence as a consequence of tunnelling operations: 1 = Tunnel lining; 2 = Part of lining additionally reinforced; 3 = Collapse; 4 = Cave origin as a consequence of collapse; $5=$ Empty cavernous space below tunnel tube; $6=$ Cave deposits (clay, sand, and limestone blocks); $7=$ Limestone; $8=$ Borehole; 9 = Fault. 


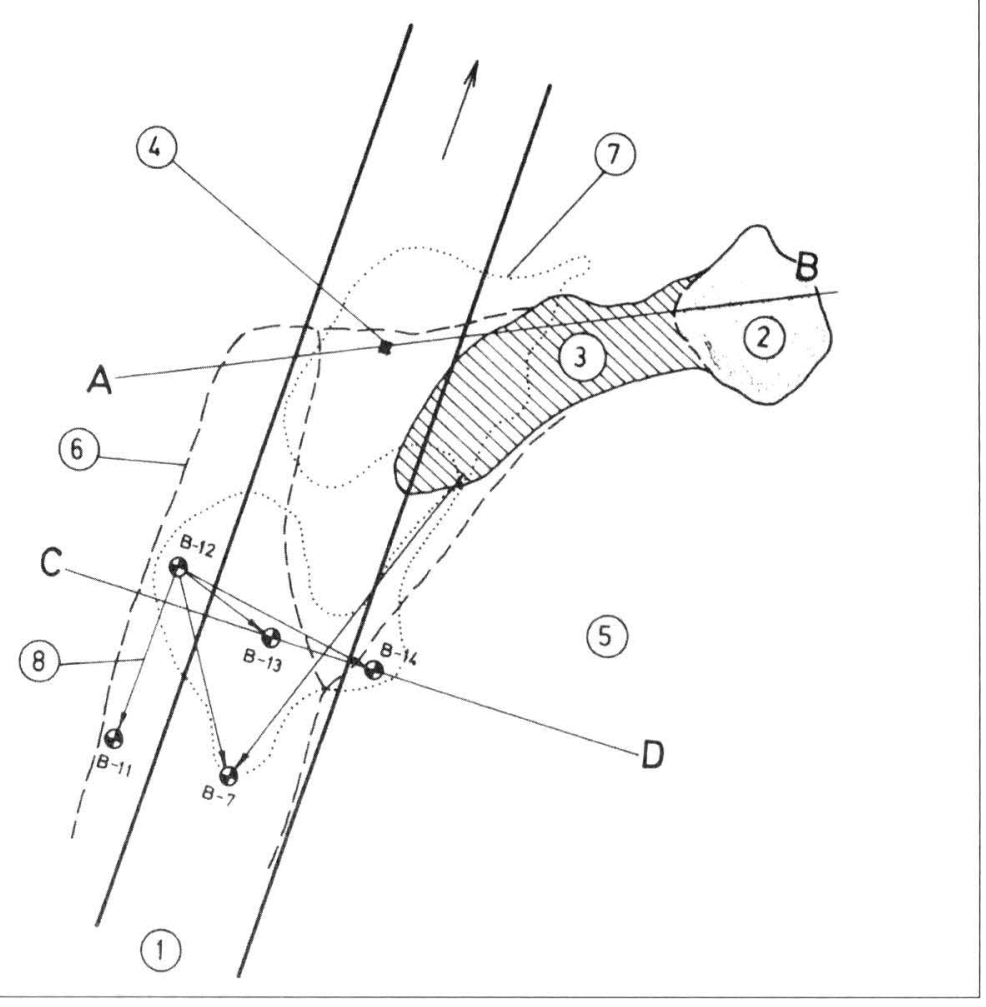

Fig. 13 - Headrace tunnel for HPP Capljina. Cavern contours.

$1=$ Tunnel; 2 = Subsidence; $3=$ Cavern, originated as a consequence of subsidence; $4=$ Shaft cut through the lined invert; $5=$ Limestone; $6=$ Cavern contour line below the tunnel lining; $7=$ Cavern contour line above the tunnel tube; and $8=$ Connection established by smoke tracer.

\section{REFERENCES}

MILANOVIC P., VUCIC M. and JOKANOVIC V. 1987. A cavern around power plant headrace tunnel tube. 197-201. In: HANRANHAN E.T., ORR T.L.L. and WIDDIS T.F. (Eds.) Groundwater effects in geotechnical engineering. A.A.Balkema: Rotterdam.

MILANOVIC P. 2000. Geological Engineering in Karst. Zebra Publishing Ltd: Belgrade.

MILANOVIC P. 2002. The environmental impacts of human activities and engineering constructions in karst regions. Episodes, Journal of International Geosciences 25 (1): 13-21.

PANTZARTZIS P., EMMANUILIDIS G., KRAPP. and MILANOVIC P. 1993. Karst phenomena and dam construction in Greece. 65-74. In: Gunay G., Johnson I. and Back B. (Eds.) Hydrogeological Processes in Karst Terrains. IAHS Publ. No 207. 